\title{
Repair of a wide lower extremity defect with cross-leg free transfer of latissimus dorsi and serratus anterior combined flap: a case report
}

\author{
Gursel Turgut $\cdot$ Mahmut Ulvi Kayalı • \\ Özkan Köse $\cdot$ Lütfü Baş
}

Received: 12 September 2008/Accepted: 24 August 2010/Published online: 18 September 2010

(C) The Author(s) 2010. This article is published with open access at Springerlink.com

\begin{abstract}
Composite tissue loss in extremities involving neurovascular structures has been a major challenge for reconstructive surgeons. Reconstruction of large defects can only be achieved with microsurgical procedures. The success of free flap operations depends on the presence of healthy recipient vessels. In cases with no suitable donor artery and vein or in which even the use of vein grafts would not be feasible, the lower limb can be salvaged with a cross-leg free flap procedure. We present a case with a large composite tissue loss that was reconstructed with cross-leg free transfer of a combined latissimus dorsi and serratus anterior muscle flap. This case indicates that this large muscle flap can survive with the cross-leg free flap method and this technique may be a viable alternative for large lower extremity defects that have no reliable recipient artery.
\end{abstract}

Keywords Lower extremity reconstruction .

Cross-leg bridge anastomosis .

Latissimus dorsi serratus anterior free flap · Combined

\section{Introduction}

Composite tissue loss in extremities involving neurovascular structures has been a major challenge for reconstructive surgeons. Principles of reconstruction cascade

G. Turgut · M. U. Kayalı $(\bowtie) \cdot$ L. Baş

Department of Plastic Reconstructive Surgery,

Sisli Etfal Research Hospital, Istanbul, Turkey

e-mail: mkayali@gmail.com

Ö. Köse

Orthopedics and Traumatology Clinic,

Diyarbakır State Hospital, Diyarbakır, Turkey dictate first using local and regional tissues. However, local and regional flaps may not be suitable for larger defects, and adequate fresh tissue can only be obtained with microsurgical procedures. The success of free flap operations depends on the presence of healthy recipient vessels. In cases with no suitable recipient artery and vein or in those where even the use of vein grafts would not be feasible, the lower limb could be salvaged through a cross-leg free flap procedure [1].

The cross-leg free flap procedure was first described by Taylor et al. in 1979 [2]. In this technique, the vascular pedicle of the free flap is temporarily anastomosed to the recipient vessels of the contralateral leg and then detached after obtaining sufficient revascularization of the flap.

Cross-leg free muscle flaps of large volume such as the latissimus dorsi have been described before [3-5]. These bulky flaps have mass effect and were shown to be effective in prevention of osteomyelitis.

We present a case with a large composite tissue defect that even a latissimus dorsi free flap would not have been adequate. Therefore, we combined latissimus dorsi with serratus anterior and transferred both on the same pedicle as a cross-leg free flap, using the vascular system of the contralateral leg as recipient. This case illustrates that a massive muscle flap such as the combined latissimus dorsi and serratus anterior can survive using the cross-leg free flap technique, and this would be a valuable option for large lower extremity defects that have no reliable recipient artery.

\section{Case report}

A 26-year-old man sustained a work-related injury to his right leg. This was an open fracture of tibia and fibula 
accompanied with a large tissue defect. He had undergone fracture stabilization by internal fixation at another institution before being referred to our outpatient clinic. After serial debridements, a soft tissue defect that constituted $70 \%$ of tibial surface was produced (Fig. 1a, b). There was hypoesthesia in dermatomes of the deep peroneal, superficial peroneal and saphenous nerves. Angiography revealed the tibialis posterior vessel was occluded due to thrombosis. The tibialis anterior artery was patent and could be seen through the whole of its course. Three weeks after the initial injury, a combined latissimus dorsi with serratus anterior muscle flap was harvested using a posterior axillary incision. The pedicles of latissimus dorsi and serratus anterior were dissected up to the thoracodorsal artery (Fig. 2). The muscles were carried to the right lower extremity defect area, and an end to end anastomosis was performed to the posterior tibial artery and vein of the contralateral leg. A split thickness skin graft was used to cover the muscle flap.

An above-knee plaster cast was applied for immobilization. Patient was immobilized in this position for 25 days. After the second week, the pedicle was constricted with a clamp and penrose drain for $15 \mathrm{~min}$ (Fig. 3). The clamping time was increased by $15 \mathrm{~min}$ on each
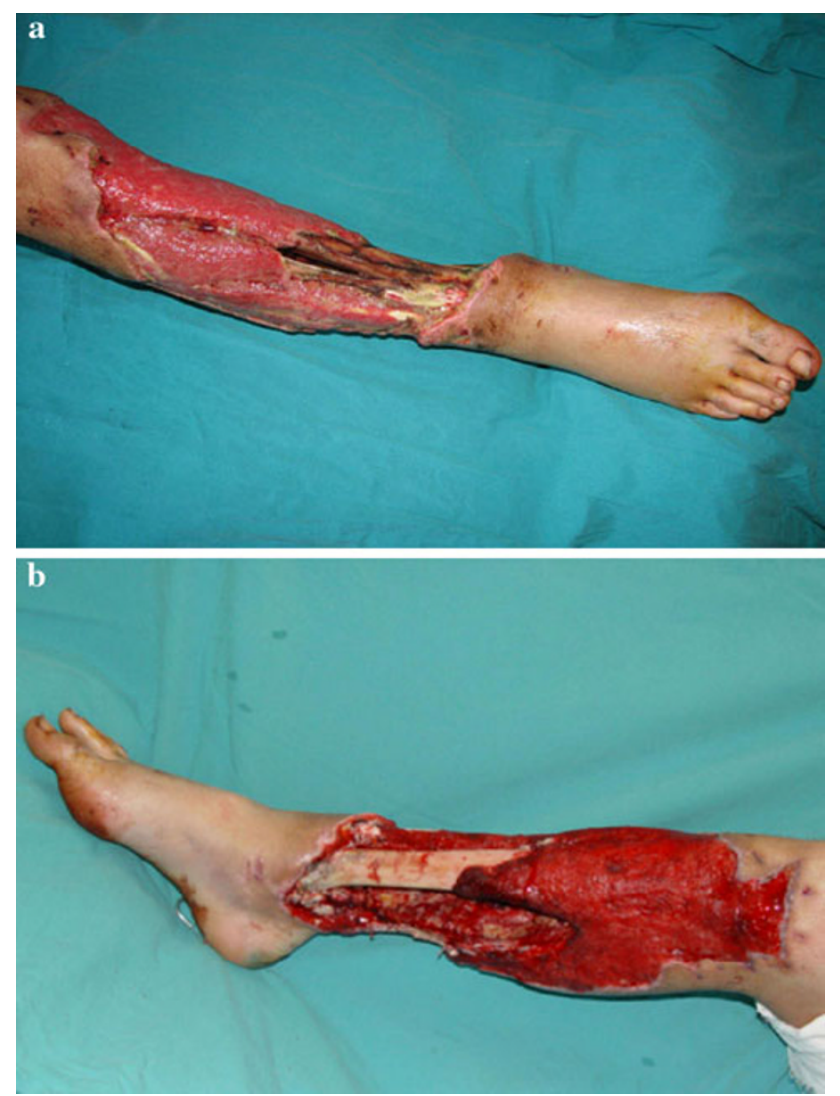

Fig. 1 a, b Following serial debridements, the uncovered tibia can be seen

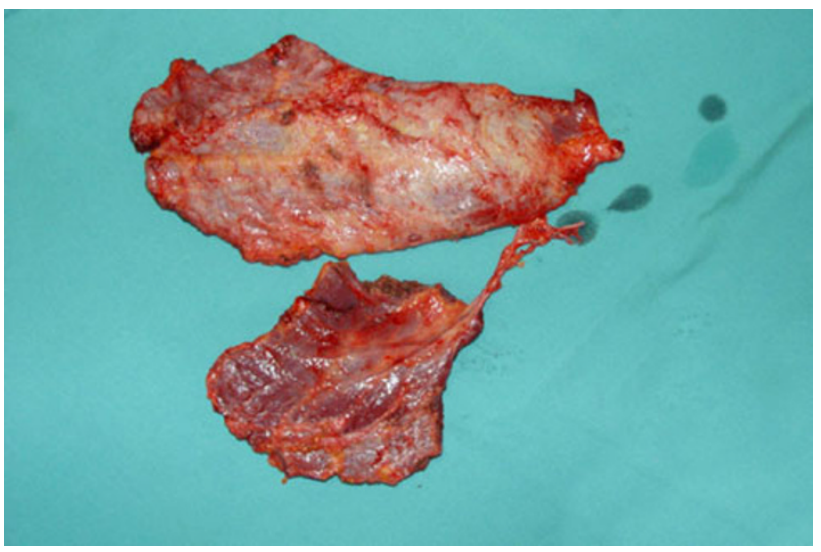

Fig. 2 Serratus anterior and latissimus dorsi muscles are elevated as in combined fashion together and dissected up to the thoracodorsal artery

consequent day. On the last 2 days, the pedicle was clamped for $2 \mathrm{~h}$ and bleeding was assessed by a needle prick test. Return of bright red blood in the distal part of the flap was taken as a sign for sufficient circulation. The pedicle was divided on the 25th day. Following division of the pedicle, vascular insufficiency was not observed in the flap. The contralateral leg healed without any complications (Fig. 4). At 8 months postoperatively, the patient was ambulatory with an Ilizarov circular external fixator (Fig. 5).

\section{Discussion}

In 1979, Taylor et al. [2] described a technique called the 'cross-leg free flap'. In his report, a free iliac osteocutaneous flap was transferred to repair a compound defect of skin and bone in a right leg. The posterior tibial artery was

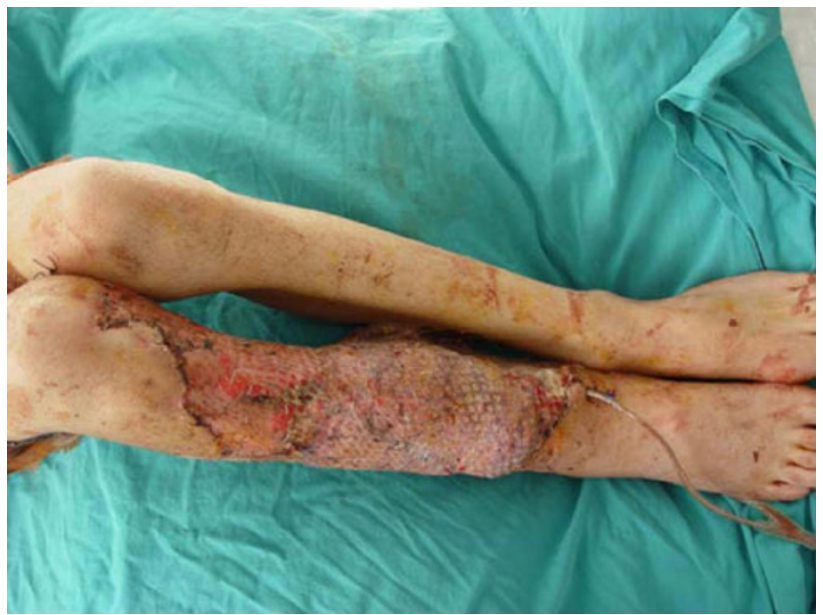

Fig. 3 The cross-leg bridge pedicle can be seen on 20th day after anastomosis 


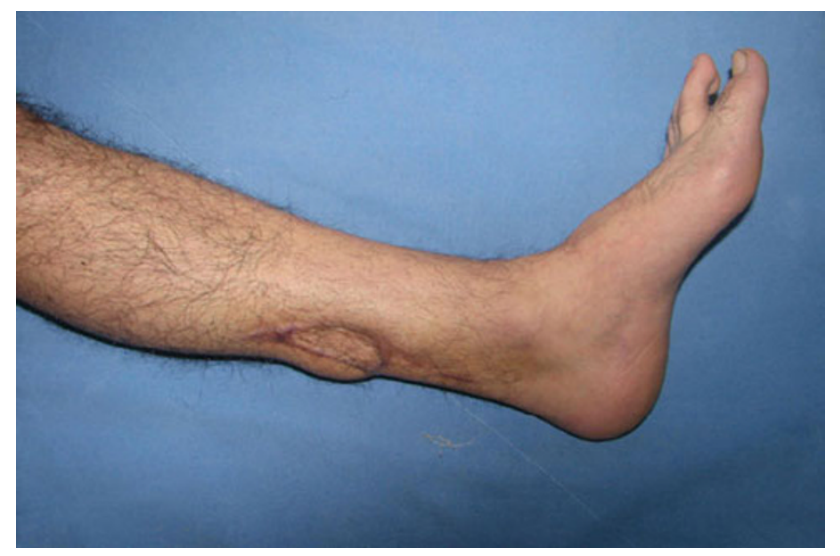

Fig. 4 At 8 months postoperatively, the contralateral leg has an acceptable aesthetic appearance and has no functional morbidity

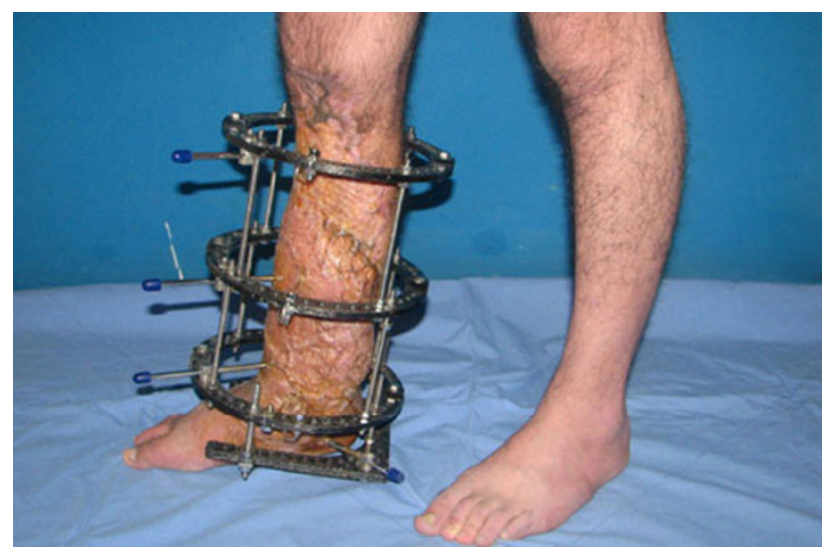

Fig. 5 At 8 months postoperatively, the patient is ambulatory with an Ilizarov device

used as the recipient artery. Following Taylor, Towsend et al. [6] reported 10 cases of cross-leg free deep circumflex iliac artery flap. Cross-leg free flap using the latissimus dorsi [3-5], rectus abdominis [7] and parascapular skin has also been described.

However, to the best of our knowledge, a combined cross-leg free transfer of latissimus dorsi with serratus anterior has not been reported in the English literature. The indications for a cross-leg free flap procedure are limited to the following: (1) lack of adequate recipient vessels in the wound with prominent swelling so that patency of long vein grafts would be difficult to maintain; (2) dissection of proximal vessels would be time-consuming (in re-exploration cases that require immediate revascularization) [8].

It has been reported that in salvage procedures of the lower extremity, the vessels in the adductor canal of the same extremity could be used as recipient vessels. A combined latissimus dorsi with serratus anterior transfer was also reported previously by Burd [9] as a salvage procedure. However, this case was referred to our hospital on 10th day after injury. Serial debridements were needed to remove the necrotic tissue and control infection until the third week. Although the infection and tissue necrosis had regressed, there was still extensive tissue oedema. Moreover, the adductor canal was close to the zone of injury, and a vein graft would be required between the vessels to establish an anastomosis. We decided that a vein graft anastomosis in oedematous tissue near the zone of injury would increase the risk of failure of both anastomosis and flap.

We did not cover the granulation tissue with a split thickness skin graft at the proximal part of the defect. The reason was muscle flaps have a different type of revascularization pattern; in that, they do not contain a subdermal plexus and need a longer time to develop revascularization. Instead, we used this granulation tissue as a bed for revascularization of the huge muscle flap. This good vascularized granulation tissue accelerated revascularization and the point at which the pedicle could be divided. The division (separation, detachment) time of the pedicle can vary according to the vascularity of the recipient bed as well as the contact area between the flap and the recipient bed.

Yu et al. [10], in an experimental study, showed that a transferred free flap can obtain a sufficient and reliable blood supply from the collateral circulation alone rather than from the vascular pedicle after 3 weeks. Chen et al. [8] reported that a 3-week period for skin flaps and a 4-week period for muscle flaps were enough for revascularization. Townsend et al. [6] recommended a delay procedure before complete division of the pedicle. We had clamped the pedicle temporarily after the second week starting with $15 \mathrm{~min}$ and increased the clamping time by $15 \mathrm{~min}$ on each consequent day. On the last 2 days, we monitored the distal part of the flap with a needle prick test. Fresh blood was assumed as a sign for sufficient revascularization.

The cross-leg microvascular anastomosis technique is now successfully used for various types of free flaps in composite tissue defects. It is also used for bone and soft tissue transfer. The anterolateral thigh (ALT) flap is another alternative for reconstructing large defects with the cross-leg free flap method [11]. Very large (up to $25 \mathrm{~cm}$ long and $18 \mathrm{~cm}$ wide) ALT flaps can be harvested. However, an anterolateral fasciocutaneous flap at that size could not cover this patient's defect. Additionally, muscle flaps have shown to be effective in preventing osteomyelitis [12]. This patient had a grade IIIC open fracture (according to Gustilo-Anderson classification) with an increased risk of osteomyelitis.

In this case, the serratus anterior and latissimus dorsi muscles were elevated on the same pedicle. Combined serratus anterior and latissimus dorsi flap was first reported 
by Harii et al. [13]. Elevation of two muscles on the same pedicle provided successful coverage of a wide defect. One donor area incision was used, so scarring and morbidity was limited and, because there was only one pedicle, one anastomosis was created for two muscle flaps and this enhances anastomosis safety. Immobilization in a cross-leg position for a month and the utilization of vessels of the healthy leg are the disadvantages of this technique. Another disadvantage is that additional blood supply to the leg is not provided. However, it has been reported that a crossfree flap can function as a nutrient flap when it is long enough to bridge across the zone of injury [8]; it brings the blood supply to the distal leg or foot and improves the circulatory status.

In conclusion, a cross-leg free latissimus dorsi and serratus anterior combined flap can provide a solution for large soft-tissue defects in lower extremities especially when there is an absence of any suitable recipient artery and vein or when even the use of vein grafts would not be feasible.

Open Access This article is distributed under the terms of the Creative Commons Attribution Noncommercial License which permits any noncommercial use, distribution, and reproduction in any medium, provided the original author(s) and source are credited.

\section{References}

1. Topalan M (2000) A new and safer anastomosis technique in cross-leg flap procedure using the dorsalis pedis arterial system. Plast Reconstr Surg 105:710-713
2. Taylor GI, Townsend P, Corlett R (1979) Superiority of the deep circumflex iliac vessels as the supply for free groin flap. Plast Reconstr Surg 64:595-604

3. Yu ZJ, Tang CH, Ho HG (1985) Cross bridge skin flap transfer: a case report. J Reconstr Microsurg 1:309-311

4. Yamamoto M, Kaji S, Mrakami Y, Yamanobe Y, Nakamura M (1992) The use of a cross-leg freeflap for the repair of an extensive injury of the lower extremities. Jpn J Plast Reconstr Surg 35:539

5. Ding SY (1993) Treatment of chronic osteomyelitis of the leg with free latissimus dorsi myocutaneous flap anastomosed to contralateral leg vessels. Chin J Plast Surg Burns 9:106

6. Townsend PLG (1987) Indications and long term assessment of 10 cases of cross-leg DCIA flaps. Ann Plast Surg 19:225-233

7. Yamada A, Harii K, Ueda K, Asato H, Tanaka H (1995) Versatility of a cross-leg free rectus abdominis flap for leg reconstruction under difficult and unfavorable conditions. Plast Reconstr Surg 95:1253-1257

8. Chen H, El-Gammal TA, Wei F, Chen H, Noordhoff MS, Tang Y (1997) Cross-leg free flaps for difficult cases of leg defects: indications, pitfalls, and long-term results. J Trauma 43(3): 486-491

9. Burd A, Ahmed K, Noronha FV, Chan JY, Pang PC (2006) Surgical reconstruction of attempted suicide charcoal burns. J Burn Care Res 27(3):330-332

10. Yu ZJ, Huang MJ, Zheng L (1984) Influence of pedicle severance at different time on the survival of canine skin flap. Chin Med J 64:449

11. Serel S, Kaya B, Demiralp O, Can Z (2006) Cross-leg free anterolateral thigh perforator flap: a case report. Microsurgery 26(3):190-192

12. Mathes SJ, Alpert B, Chang N (1982) Use of the muscle flap in chronic osteomyelitis: experimental and clinical correlation. Plast Reconstr Surg 69:815-829

13. Harii K, Yamada A, Ishihara K, Miki Y (1982) A free transfer of both latissimus dorsi and serratus anterior flaps with thoracodorsal vessel anastomoses. Plast Recons Surg 70:620-629 